\title{
BMJ Global Health Health system effects of implementing integrated community case management (iCCM) intervention in private retail drug shops in South Western Uganda: a qualitative study
}

\author{
Freddy Eric Kitutu, ${ }^{1,2,3}$ Chrispus Mayora, ${ }^{2,4}$ Emily White Johansson, ${ }^{3}$ \\ Stefan Peterson, ${ }^{2,3,5}$ Henry Wamani, ${ }^{2}$ Maryam Bigdeli, ${ }^{6}$ Zubin Cyrus Shroff ${ }^{7}$
}

To cite: Kitutu FE, Mayora C, Johansson EW, et al. Health system effects of implementing integrated community case management (iCCM) intervention in private retail drug shops in South Western Uganda: a qualitative study. BMJ Glob Health 2017;2:e000334. doi:10.1136/ bmjgh-2017-000334

- Additional material is published online only. To view, please visit the journal online (http://dx.doi.org/10.1136/ bmjgh-2017-000334).

Received 1 March 2017 Revised 27 June 2017 Accepted 30 June 2017

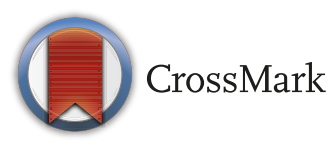

For numbered affiliations see end of article.

Correspondence to Freddy Eric Kitutu; freddy.kitutu@kbh.uu.se, kitutufred@gmail.com

\section{ABSTRACT}

Background Intervening in private drug shops to improve quality of care and enhance regulatory oversight may have health system effects that need to be understood before scaling up any such interventions. We examine the processes through which a drug shop intervention culminated in positive unintended effects and other dynamic interactions within the underlying health system. Methods A multifaceted intervention consisting of drug seller training, supply of diagnostics and subsidised medicines, use of treatment algorithms, monthly supervision and community sensitisation was implemented in drug shops in South Western Uganda, to improve paediatric fever management. Focus group discussions and in-depth interviews were conducted with stakeholders (drug sellers, government officials and community health workers) at baseline, midpoint and end-line between September 2013 and September 2015. Using a health market and systems lens, transcripts from the interviews were analysed to identify health system effects associated with the apparent success of the intervention.

Findings Stakeholders initially expressed caution and fears about the intervention's implications for quality, equity and interface with the regulatory framework. Over time, these stakeholders embraced the intervention. Most respondents noted that the intervention had improved drug shop standards, enabled drug shops to embrace patient record keeping, parasite-based treatment of malaria and appropriate medicine use. There was also improved supportive supervision, and better compliance to licensing and other regulatory requirements. Drug seller legitimacy was enhanced from the community and client perspective, leading to improved trust in drug shops.

Conclusion The study showed how effectively using health technologies and the perceived efficacy of medicines contributed to improved legitimacy and trust in drug shops among stakeholders. The study also demonstrated that using a combination of appropriate incentives and consumer empowerment strategies can help harmonise common practices with medicine regulations and safeguard public health, especially in mixed health market contexts.
Summary box

What is already known about this topic?

- Private retail drug shops are an important source of care and management of paediatric fevers, especially in low-income and middle-income countries; however, the quality of care offered needs to be improved.

What are the new findings?

- Using a package of market incentives can alter the behaviour of market agents and improve agent practices.

- Furthermore, intervening in private health markets could generate health system effects beyond the market itself.

How might this impact on practice?

- Health systems have complex and dynamic interactions and therefore intervention designs must recognise these complexities.

- Intervention evaluation models must adopt a systems approach to analyse broader impact.

\section{INTRODUCTION}

Acute febrile illnesses of malaria, acute respiratory illness and diarrhoea account for more than half of deaths among children aged 1-59 months globally. ${ }^{1}$ Majority of fever cases in low-income countries (LICs) such as Uganda seek care from private drug shops, ${ }^{23}$ which have good reach in communities. Compared with government health facilities, drug shops are more accessible in terms of convenience, cost and time spent on careseeking, and they have more reliable stocks of medicines and better social relations with their clients. $^{4-6}$ Clients are aware that they provide income to drug sellers and hence are able to exert agency in the care-seeking process. ${ }^{7}$ In 
contrast to encounters with government health workers, clients are active customers rather than passive patients in an interaction with health providers that is friendly, and in which their opinions are respected. ${ }^{589}$ However, drug shops operate in a largely unregulated retail health market where infringements of medicine regulations are commonplace. ${ }^{910}$ They fill a void created by the absence of government and formal private health services in hardto-reach communities. ${ }^{910}$

In Uganda, drug shops are part of an overall health system characterised by blurry boundaries between government-run and privately owned health facilities. $^{9-11}$ Government health workers supplement their incomes by working at private drug outlets, ${ }^{10}{ }^{12}$ charge unofficial fees ${ }^{613}$ and they often advise patients to source medicines from private drug outlets in the face of stock outs at government health facilities. ${ }^{5} 1415$ Challenges faced by the health sector are compounded by high levels of poverty, with half of the population subsisting on $<$ US $\$ 1.25$ per day and a gross national income per capita of US\$680. ${ }^{16}$ Uganda is a low-income country and the government contribution to health of US $\$ 13.7$ per capita $^{17}$ leaves health services severely under-resourced. Thus, out-of-pocket expenditure is high at $40 \%$ of total health expenditure ${ }^{18}$, and technical quality of health services at low-level health facilities is poor. ${ }^{311}$ This leads to catastrophic expenditures for households, it endangers under-five (U5) child health and nutritional status ${ }^{3}$ and it perpetuates inequality. With regard to health indicators, the U5 mortality rate is 55/1000 live births, neonatal mortality rate is $23 / 1000$ live births and infant mortality rate is $53 / 1000$ live births.$^{16} 1719$

With most Ugandans (97\%-99\%) at risk of Plasmodium falciparum infection, ${ }^{20}{ }^{21}$ malaria is a leading cause of mortality. Other illnesses also present as acute febrile episodes. Therefore, presumptive treatment of all fevers with antimalarial medicines or antibiotics, as occurs in drug shops, is no longer recommended or acceptable. It delays seeking appropriate treatment and promotes an overuse of antimicrobials, which are known to promote resistant strains and to waste scarce healthcare resources. Without significant investment in scaling up public sector health services, care-seeking from drug shops in rural areas will continue. Drug shops operate in a retail market largely influenced by care-seeker preferences, provider incentives, drug sellers' reputations in the institutional environment and the pharmaceutical supply chain, ${ }^{42}$ and sometimes these influences diverge from promoting public health. They can pose a challenge for health market regulation, to assure that good quality, affordable and equitable, healthcare services are provided to the population at a reasonable price while maintaining accountability to society. ${ }^{23} 24$

Top-down interventions by governments to enhance regulatory oversight such as government enforcement of 'unrealistic' practice standards can be impractical and undesirable, and may adversely affect access to medicines for children. They are likely to be interpreted by drug sellers as interference in their market space, as reported by the study by Goodman et al in Tanzania, ${ }^{25}$ and could be met with resistance and evasion. If such interventions are to succeed in enhancing population health, scholars recommend that their implementation take into account a systems thinking perspective. These scholars argue that interactions among the various components of these interventions, and the intended and unintended consequences on the diverse range of stakeholders be kept in mind. $^{25} 26$

We conducted an intervention study to evaluate the effect of an integrated community case management (iCCM) for childhood illnesses intervention ${ }^{27-29}$ on paediatric fever care in licensed drug shops, in a low malaria transmission setting of South Western Uganda, ${ }^{30} 31$ between May 2013 and September 2015. The intervention consisted of multiple components (described below) and it is referred to as the AXEX (access and excess) intervention for simplicity. Using a factorial model, we conceptualised the intended effects on drug seller treatment practices into predefined discrete, static and quantifiable variables. ${ }^{32}$ We measured and compared appropriate management of childhood febrile cases (intended effects) in the intervention and comparison arm, before and after the AXEX intervention. Trained enumerators collected data in care-seeker drug shop exit interviews. The AXEX intervention improved appropriate treatment of uncomplicated malaria by $80 \%$, of acute respiratory infection by $66 \%$ and of non-bloody diarrhoea by $31 \%$. Results of these predefined (intended) effects have been discussed in detail elsewhere. ${ }^{33}$

However, it is important to understand the context, as well as the intervention's implementation and mechanism of effect, to better interpret the outcomes. ${ }^{34}$ The hypothesis for this paper borrows from Robert Merton's social theory, and we argue that the AXEX intervention, like other purposive social actions, has unintended consequences. ${ }^{35}$ Some of these can be foreseen and prevented, and others cannot be predicted. Whereas the intended and anticipated consequences of the purposive action are always relatively desirable to the actor, unintended effects are not always undesirable. In this paper, we adopt a health market theoretical framework $^{37}$ to describe and analyse the AXEX intervention. We aim to understand how the AXEX intervention was implemented, its intended and unintended consequences and their interconnections, and examine the dynamics and processes by which the effects were achieved.

Other studies have reported on the effects of child survival interventions in drug shops in Uganda. ${ }^{5911} 1438-40$ On the subject of unintended consequences of introducing malaria Rapid Diagnostic Tests (mRDT) in drug shops, Hutchinson et al report that mRDTs interact with care-seeker desire for trustworthy providers and are useful in targeting medicines for their illness. ${ }^{40}$ However, inadequate regulation of retail drug shops makes the mRDT appear more powerful than it is. ${ }^{40}$ Our study goes farther than analysing the processes 
through which mRDTs became part of the assemblage in the drug shop space. Our study evaluates a social franchising system, which is currently popular among global health actors despite the lack of sound empirical evidence on its role or effects. ${ }^{41}$ It incorporates an account of components that would improve the regulation of drug shops and retail health markets and forge formal linkages to government health services, which is missing in previous studies. ${ }^{5}{ }^{38}$ Lastly, it evaluates the iCCM of childhood febrile illnesses rather than just malaria tests. Our paper provides important lessons on the design and implementation of multicomponent interventions that seek to improve access to medicines and quality health services through an often neglected-yet critical-group of healthcare providers in low-and-middle-income countries (LMICs).

\section{Implementation of the AXEX intervention}

The implementing team included Makerere University School of Public Health in collaboration with the Alliance for Health Policy and Systems Research, World Health Organization, Karolinska Institutet and Uppsala University. A prospective evaluation of the AXEX intervention in 61 registered drug shops was done in Mbarara district from May 2013 to September 2015. Mbarara is located approximately $250 \mathrm{~km}$ South West of Kampala, the Ugandan commercial and administrative capital. ${ }^{31}$ The district had a population of 472629 people served by 58 government health facilities, private medicine outlets and the informal sector. The South Western region has a typical tropical climate with rainfall peaks in April and October. ${ }^{16}$ Recent surveillance studies estimate the malaria parasite prevalence in the region to be between $4.1 \%^{31}$ and $9.3 \% .^{30}$

The AXEX intervention adapted the integrated case management intervention ${ }^{28}{ }^{42}$ recommended by WHO/ UNICEF $^{28}{ }^{42}$ and the Ugandan Ministry of Health $(\mathrm{MoH}){ }^{27}$ It consisted of three components that were adapted for implementation in private licensed drug shops.

The first was the drug seller component that aimed to improve integrated case management skills for those tending to U5 febrile child, based on case detection using simple clinical signs and rapid diagnostics to guide choice of treatment. Drug sellers from enrolled licensed drug shops were trained by a MoH-certified trainer. Using the MoH iCCM curriculum, drug sellers attended a 6-day training of lectures and hands-on sessions. It addressed how to assess, test, classify and treat the childhood illnesses of malaria, acute respiratory illness (ARI) and diarrhoeal diseases. Use of diagnostic testing, referral, filling in registers and managing drug supplies were also explained. Monthly support supervision was done by a project pharmacist or clinician to reinforce the skills acquired.

The second was the service component, which focused on the distribution of medicines, diagnostics and other logistics necessary for service provision. Medicines included artemether-lumefantrine dispersible tablets (DT), DT amoxicillin, DT zinc, oral rehydration salts (ORS) and artesunate suppositories. The medicines were single dose-packaged and colour-coded for specific age groups. The diagnostics included mRDT, specific for $P$. falciparum and respiratory counters. Other logistics included access to life (A2L) sign posts to mark study drug shops, drug shop registers, referral slips, resupply order forms (to enable uninterrupted supply of medicines) and treatment algorithms. The medicines (at subsidised price) and diagnostics (free-of-charge) could be procured from the pharmaceutical wholesaler in the nearest town to the study area on presentation of the resupply order forms. This was to ascertain that the medicine supply was from a trusted source and also to be able to channel the subsidy to the study drug shops.

The third was a community component, which sought to improve household and community care-seeking practices with potential impact on U5 child health. To this end, messages on fever care-seeking, diagnostic testing and treatment adherence were delivered through community health workers (CHWs), radio talk shows and announcements and by word-of-mouth by community members. CHWs interacted directly with the AXEX intervention team in quarterly project workshops.

\section{Theoretical framework}

We adapted the theoretical framework (figure 1) for health market systems proposed by Bloom et $a l^{43}$ to take into account key stakeholders in Uganda.

At the centre of the framework, are care-seekers as users interacting with drug sellers as health providers, and this interaction is affected and shaped by support functions that include institutional ${ }^{i}$ arrangements, infrastructure, information and related services shown in the middle (grey) concentric circle. The components of the AXEX intervention (explained above) acted on these support functions and introduced new ones. The outer most concentric circle lists the other market players who influence and are affected by the support functions.

A review of the relevant literature, in-depth interviews and focus group discussions (FGDs) were used to gather data for this study. In the initial phase, stakeholders, also referred to as actors or market players were identified through a desk review of relevant literature and consultation with professional organisations and personnel, ${ }^{44}$ informed by the authors' perception of the position or influence they may hold.

Five key player categories were identified through this process, namely: i) health providers (drug shop owners, sellers and community health workers (CHWs)); ii) beneficiaries (care-seekers); iii) central government agencies $(\mathrm{MoH}$ and the National Drug Authority (NDA)); iv) local government institutions of Mbarara and, v)

${ }^{\mathrm{i}}$ The term institutional here refers to rules, laws, norms and customs, and is distinct from its synonym organisational which refers to social settings. 


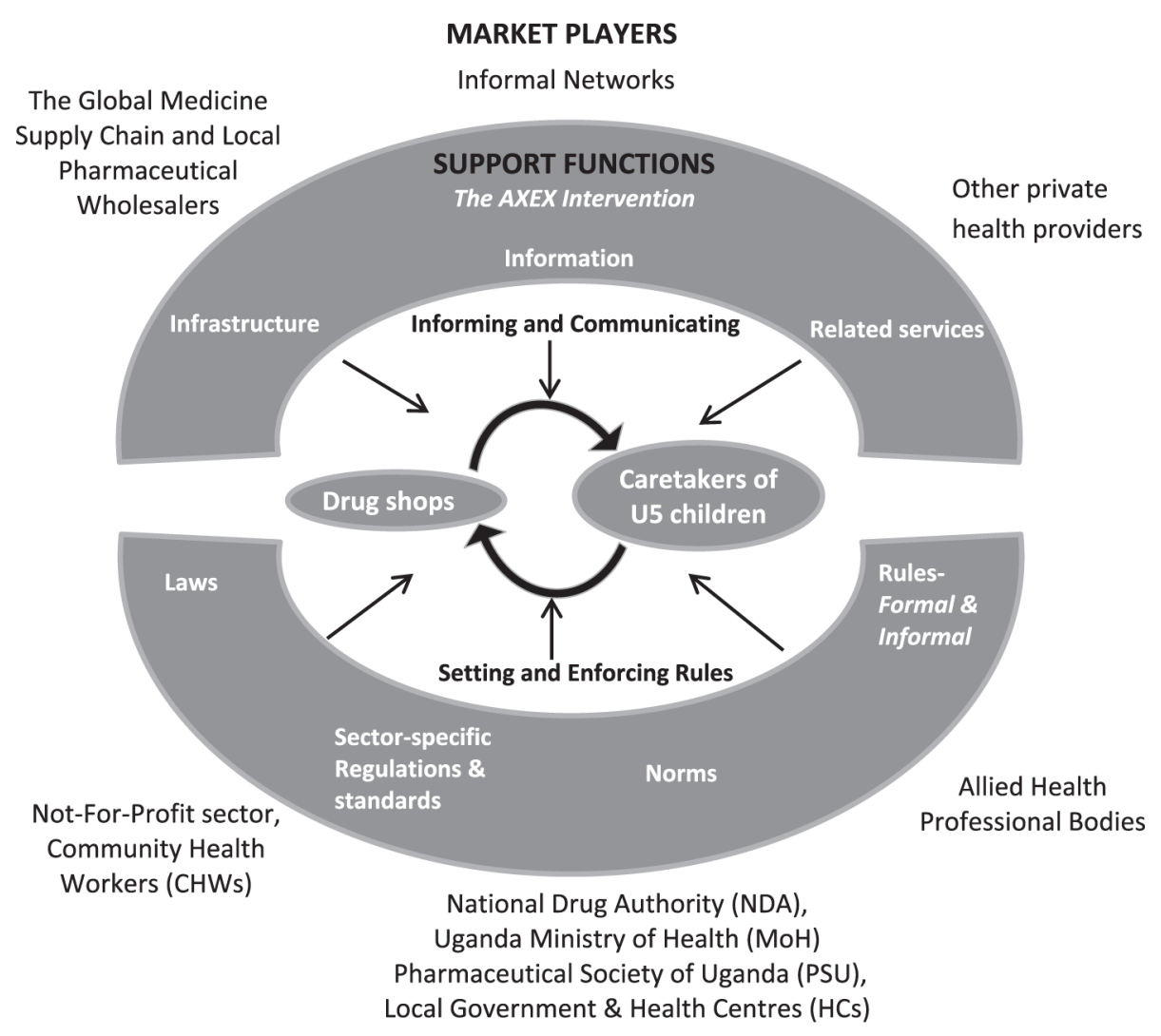

Figure 1 Theoretical framework for the access and excess (AXEX) intervention in drug shops in a mixed health system.

pharmaceutical supply chain actors (manufacturers and wholesalers). Other stakeholders were not-for-profit health providers, health professional bodies (Pharmaceutical Society of Uganda (PSU) and allied health professional council), other private health providers outside the study and the global pharmaceutical supply chain.

\section{METHODS}

At baseline, we explored common childhood illnesses treated at the drug shops, why community members sought care from them, and challenges care-seekers and drug sellers faced. Drug sellers were asked about their interactions with care-seekers, community health workers, how they obtained operation permits and experiences of their encounters and interactions with district and NDA officials. Care-seekers, drug sellers and community health workers were asked about their sources of health and medicine information. Drug sellers, care-seekers and community health workers were asked hypothetically about their views and perceptions on implementing an intervention that trained drug sellers to use diagnostic tests to assess and classify children, prior to recommending medicines or otherwise. These interviews aimed to understand the positions occupied by each of the key stakeholders within the theoretical framework for retail health markets in mixed health systems. They also highlighted the direct and indirect relationships and interactions among them. Midline and end-line interviews asked similar questions with a focus on first-hand accounts of experiences with the intervention or its components, perceptions formed, emergent opinions among the key stakeholders and challenges and opportunities posed by the AXEX intervention.

\section{DATA COLLECTION}

A team composed of a social scientist, graduate in Bachelor of Arts and a pharmacist conducted face-to-face interviews using interview guides. Participants were purposively selected; drug sellers in study drug shops were invited to participate in the in-depth Interviews (IDIs) and care-seekers at baseline were identified by CHWs. The inclusion criteria were having a child U5 as a dependent and previous care-seeking from private drug shops. CHWs within the catchment area of the drug shop were enrolled for FGDs. Data collection methods and stakeholders are listed in table 1.

Baseline data collection was done in May 2013 and an end-of-study evaluation was done in June and July 2015. Care-seekers who participated in FGDs were those with an U5 child who had sought care from a drug shop in the 2 months preceding data collection. CHWs participated in the FGDs if they were resident in the study area. FGDs were conducted in the study area at locations deemed convenient to participants including at subcounty halls, school classrooms and at health centres (HCs).

IDIs with drug sellers were conducted at their drug shops and IDIs with government officials were held at their offices. Sample sizes for all categories of FGDs and IDIs 
Table 1 Number of focus group discussions and in-depth interviews conducted

\begin{tabular}{|c|c|c|c|c|c|}
\hline Data collection method & Stakeholder & Baseline & Midline & End-line & Total \\
\hline \multirow[t]{2}{*}{ Focus Group Discussions } & Care-seekers with under-five child & 6 & 7 & 5 & 18 \\
\hline & Community Health Workers & 6 & & 2 & 8 \\
\hline In-depth Interviews & Government officials* & 4 & 10 & 5 & 19 \\
\hline
\end{tabular}

${ }^{*}$ Government officials included district health team, officials of drug regulatory agency and Ministry of Health and government health centre personnel.

were determined by topical saturation. ${ }^{45}$ Written informed consent was obtained from participants for the study and to digitally record the interviews. At the end of each interview, the lead interviewer or facilitator, note taker and lead author debriefed to improve the interview guide. Each interview was transcribed and translated into English by bilingual research assistants under supervision of the lead author. The lead author maintained a field journal and had a record of project activity reports. Total numbers of participants per interview and background characteristics are shown in table 2.

\section{Data management and analysis}

All interviews and conversations were audio-recorded and complemented by field notes. The lead author checked all the transcripts against the recordings to ensure accuracy, and reviewed and cleaned the transcripts. All transcripts were carefully read multiple times by the authors FEK (lead) and CK, and they were separately coded in OpenCode Software V.4.03 (University of Umeà, Sweden) ${ }^{46}$ using the content and thematic analysis approach. ${ }^{47}$ Data were extracted into meaning units. Together with predefined areas of interest identified from the theoretical framework for health market systems, the meaning units were used to draw up the initial coding scheme. Preliminary codes were refined by the lead author and applied back to the transcripts. These were further refined into final categories that reflected actual experiences and encounters of the different stakeholders with all or some of the components of the AXEX intervention.

At baseline, the overarching aim of the analysis and iterative process was to understand the roles and functioning of each key stakeholder and how those roles and functions

Table 2 Numbers and background characteristics of the participants

\begin{tabular}{|c|c|c|c|c|c|}
\hline Characteristic & Description & Drug sellers & Care-seekers & $\begin{array}{l}\text { Community health } \\
\text { workers }\end{array}$ & $\begin{array}{l}\text { Government } \\
\text { officials }^{\star}\end{array}$ \\
\hline $\begin{array}{l}\text { Data collection } \\
\text { method }\end{array}$ & & IDIs & FGDs & FGDs & IDIs \\
\hline $\begin{array}{l}\text { Number of } \\
\text { respondents }\end{array}$ & & 47 & 154 & 50 & 29 \\
\hline $\begin{array}{l}\text { Respondents per } \\
\text { interview }\end{array}$ & & 1 & 5 to 11 & 4 to 8 & 1 \\
\hline \multirow[t]{2}{*}{ Sex } & Female & $40(85 \%)$ & $139(90 \%)$ & $30(60 \%)$ & $14(48 \%)$ \\
\hline & Male & $7(15 \%)$ & 15 (10\%) & $20(40 \%)$ & $15(52 \%)$ \\
\hline \multirow[t]{3}{*}{ Marital status } & Married & $22(46 \%)$ & $95(62 \%)$ & 47 (94\%) & - \\
\hline & Cohabiting & $7(15 \%)$ & $48(31 \%)$ & 0 & - \\
\hline & Single & $18(39 \%)$ & $11(7 \%)$ & $3(6 \%)$ & - \\
\hline \multirow{5}{*}{$\begin{array}{l}\text { Highest level of } \\
\text { education }\end{array}$} & Degree & - & $1(1 \%)$ & 0 & $7(24 \%)$ \\
\hline & A-level or certificate & - & $19(12 \%)$ & $5(10 \%)$ & $22(76 \%)$ \\
\hline & O-level & & $37(24 \%)$ & 27 (54\%) & 0 \\
\hline & Primary & & $83(54 \%)$ & $18(36 \%)$ & 0 \\
\hline & None & & $14(9 \%)$ & 0 & 0 \\
\hline \multirow[t]{2}{*}{ Work experience } & 3 or more years & - & - & $48(96 \%)$ & $28(97 \%)$ \\
\hline & $<3$ years & - & - & $2(4 \%)$ & $1(3 \%)$ \\
\hline Mean age (range) & & $\begin{array}{l}32 \\
(24 \text { to } 45)\end{array}$ & $\begin{array}{l}30 \\
(18 \text { to } 59)\end{array}$ & $\begin{array}{l}40 \\
\text { (24 to } 60)\end{array}$ & $\begin{array}{l}39.7 \\
(23 \text { to } 59)\end{array}$ \\
\hline
\end{tabular}

*At midline, only 10 IDIs (out 20) of health workers in health facilities within the catchment area of the study drug shops were included in the study.

FGD, focus group discussions; IDls, in-depth interviews. 
influenced the existing local retail health market. The lead author guided by emerging themes reflected on how implementing the AXEX intervention would alter or reinforce existing relationships and dynamic interactions. Themes around how drug sellers and care-seekers access health and medicine information, fears and negative perceptions and potential reactions towards the proposed intervention were examined. Preliminary findings subsequently led to adaptations in the implementation of the AXEX intervention.

A similar analytical and iterative process was followed at end-line. During this analysis, emerging themes, reflections and interpretations were checked against field notes and project activity reports. The lead author undertook deeper analysis, guided by the study objectives and domains from 'systems thinking' as applied to retail health markets in LMICs, ${ }^{26} 4849$ to understand how these experiences had shaped stakeholder perceptions, opinions, attitudes and behaviours at different points in the life of the AXEX intervention. The final categories at end-line included interface with the regulatory framework, information and dissemination, perceived efficacy of the AXEX intervention, linkage to the formal health system and provider incentives.

\section{FINDINGS}

Drug shops were recognised as an important source of healthcare; one that was more accessible, respectful and responsive to care-seeker needs and expectations than public facilities. ${ }^{9}$ Drug sellers were aware of their position as physically and socially closer to communities, but they were perceived by health workers in the formal HCs as existing on the margins. ${ }^{5}$ They understood that they operated in a local market influenced by knowledge and actions of care-seekers, CHWs, government health workers and regulators and also how formal and informal rules and norms were applied. ${ }^{37}$ At baseline, these actors, drug sellers inclusive were cautious of how the AXEX intervention would impact on existing relationships and interactions among actors, rules and norms in the retail health market in which drug shops operated, and whether the emerging consequences would be beneficial or detrimental to care-seekers and the community. Implementation of the AXEX intervention was in turn modified and shaped by the emerging perceptions and behaviours of the actors identified in the theoretical framework adopted for this study.

The findings are presented as follows: first, the fears, perceptions and reactions of each actor-drug sellers, care-seekers, CHWs and government officials - prior to and in the early days of implementation are reported. The second section reports the perceptions and experiences of the actors, their interactions among each other and with the multiple components of the AXEX intervention and how these shaped the intervention, from the lens of foreseen and unintended consequences as they emerged. These are presented under the following categories: interface with the regulatory framework, information and dissemination, provider incentives, linkage to the formal health system and perceived efficacy of the AXEX intervention.

\section{INITIAL FEARS, PERCEPTIONS AND REACTIONS}

The initial attitude was that of fear of regulation on the part of drug sellers, that of drug sellers' opportunistic behaviour on the part of government officials, that of loss of status in the community on part of CHWs and apprehensions of whether drug sellers had the ability to apply diagnostic testing on the part of the care-seekers, respectively.

\section{Drug sellers}

Several drug sellers viewed the AXEX intervention with caution. They had fears that either the intervention or CHWs would be disruptive to their drug shop operation and business. Some viewed it as a veiled avenue for strict enforcement of regulations by the government, as well as controlling their activities.

... when I come to understand, that you have come to take me down (interfere with my business), I leave it (the inter-

vention)... (IDI, DS3)

Most drug sellers understood the role of diagnostic testing in guiding their treatment decisions but still expressed doubts on how well the mRDTs and respiratory timers differentiated presence and absence of disease among children.

\section{Government officials}

Government officials explained that the AXEX intervention enabled them to provide permits to drug shops to sell selected antibiotics, opening the door for further loosening of regulations. In the words of a government official,

...Drugs like amoxicillin are in class B. They are not supposed to be (sold) in drug shops. Those could be the preliminary steps to see that may be, you declassify things like amoxicillin and allow it to be sold by drug shops. (IDI, GO1)

One government official stated that drug sellers tended to behave in an opportunistic manner. They sold medicines at high prices and provided some treatments that could harm children. The government official observed that they sold paracetamol and made a profit of it but then this treated the symptom and delayed care-seeking for the underlying cause in public health facilities.

\section{Community Health Workers}

Some CHWs observed that drug sellers would be hesitant to sell AXEX intervention medicines because of the pricemarking, which appeared to limit the mark-up that could be obtained. The price-marking restricted their discretion to set prices and potentially conflicted with the sale of more profitable alternative treatments.

They also felt aggrieved that the iCCM intervention, which was designed to be implemented by CHWs, was adapted to drug shops. Other complaints included assertions that most drug shops were not licensed and tended to supply inadequate doses or even wrong medicines to clients. 
In the words of a CHW,

Even if they do treat us, some of them are illegal which is not good. ... they are expensive, they give you drugs according to the amount of money you have, so you find that at times you take an under-dose which does not help you, ... the disease is not effectively treated and it recurs.

(FGD4, CHW3)

On the other hand, a few CHWs were optimistic that drug shops would provide better fever care to their communities. This thinking was rationalised in terms of drug sellers having more health-related training and higher literacy skills than CHWs.

\section{Care-seekers}

Some care-seekers occasionally questioned drug seller's adeptness to use diagnostic tools to inform choice of treatment, given their previous treatment experience with drug sellers.

In the words of a care-seeker,

You do not know how to test because we have been with you and you were not testing. Did you study how to test? Are you a laboratory technician? Then, how can you test?

(FGD3, care-seeker 2)

Other care-seekers seemed to reject the notion of pointof-care diagnostics and thus were hesitant to accept the test outcome, especially when it indicated absence of disease.

... Does this thing really work? Where is the microscope? You are not using electricity; you are not using power, where will you plug? Where are the chemicals then? (FGD4, care-seeker 3)

Care-seekers considered 'new requirements'including the need for face-to-face interactions with the child before dispensing drugs (for examination and diagnostic testing) and collection of patient information (contact and demographic information for the drug shop patient registry) - initiated by drug sellers as mundane and typical of the poor customer care seen at government health facilities.

\section{INTERFACE WITH THE REGULATORY FRAMEWORK}

Government officials revealed some challenges encountered in previous efforts at regulating drug shops. Insufficient resources, underqualified drug sellers, lack of community engagement and poor recordkeeping practices were mentioned.

...the problem is that we are constrained with the resources, both in terms of finances and human resources so there is a tendency of concentrating all our efforts to the government sector. (IDI, GO3)

Also highlighted were lack of price control regulation, minimal collaboration with district structures and opposition to interventions in drug shops by CHWs and health professional councils. Local politicians were reported to interfere with enforcement of regulatory standards as seen below:
In the words of government officials,

... and then politicians in the district protect illegal shops. There are two types (of drug shops); illegal shops-those shops managed by non-health trained people. Someone did not go to school but he is managing a drug shop. We close these ones automatically because they are a danger to society. The second type is managed by people who have gone to school, have done their certificate as nursing assistant (some health-related training), and have (previously) worked in a health facility and (now) they are working in their (drug) shop... So sometimes these politicians protect the illegal shops. (IDI, GO2)

If you try to close even an illegal drug shop, you will be surrounded (threatened). Even the Local Council one chairman (politician) will come and tell you, "You cannot do this to us". (IDI, GO1)

The government officials noted that the AXEX intervention addressed a number of these challenges by requiring drug sellers to interact with the regulatory institution in a number of areas. These included possession of a valid NDA licence to be eligible to participate in the study, adaptation and implementation of the $\mathrm{MoH}$ iCCM strategy, the use of single-dose, colour-coded packs approved by the NDA and the procurement of medicines and diagnostics via licensed pharmaceutical wholesalers, in accordance with existing regulations.

Most government officials commended the involvement of multiple stakeholders. Drug sellers observed that officials from the subcounty, HCs and district served as supervisors, mentors and health educators to enhance their practice standards, and care-seekers were sent from health facilities to purchase medicines from drug shops, on the other hand CHWs and local leaders liaised with the community.

In the words of a government official,

...you took (trained) them through ICCM and gave them malaria RDTs. And malaria RDTs are helpful in reducing the usage of antimalarial drugs, so that negative cases are not treated (given ACTs)... (IDI, GO3)

In the words of a drug seller,

...when a patient sits for a long time at the government health centre, the doctors send them to drug shops to be assisted, because sometimes there are no drugs at the government health centre. I think government should be grateful for that. (IDI, DS11)

Government officials and drug sellers alike noted that drug shops had access to novel medicines and diagnostics that were normally outside their medicine licence permits.

In the words of one drug seller,

... before going for the training, we were not allowed to do any blood tests so we got a chance to do blood tests (mRDTs). In addition, we were given a respiratory timer.' (IDI, DS6)

The community sensitisation conducted as part of the intervention was considered to have shifted customers away from unlicensed drug outlets. 
In the words of a care-seeker,

We used to go to drug shops, they would never ask us anything, we would just be given the drugs we asked for and asked to pay up and we would go our way. We would not even be explained to, why this drug cost this much and the other that much. The difference now with these new ones (drug shops) is that they cannot give you a drug without knowing what the child is suffering from. (FGD1, care-seeker 8)

This had an indirect effect that unlicensed drug outlets closed shop.

In the words of a government official,

...that also helped us by reducing the mushrooming drug shops (drug shop start-ups) which were useless and dangerous to our people "... as drug shops without valid licenses segregated (self-selected and closed business operations) themselves". (IDI, GO2)

...we used to have three or four drug shops, but some did not have enough capacity to serve, so those ones closed, and one was left. This one improved the appearance of its premises, brought equipment and the medicines. (FGD3, care-seeker 6)

Over time, some government officials considered drug sellers to be better suited than CHWs to implement the iCCM intervention and the AXEX intervention provided an avenue to review legal permits of drug shops so as to increase access to medicines and promote public-private partnerships for health (IDI, GO3).

In the words of a government official,

...We have a whole component on private sector and community engagement; private sector partnership and private sector engagement. (IDI, GO3)

Taken together, the intervention was interpreted by authors to have improved regulator-drug seller interpersonal relations and motivated drug sellers to comply with practice standards. The mutual relationships could have led to more open and meaningful interactions, necessary to improve drug shop compliance to regulations.

\section{INFORMATION AND DISSEMINATION}

Key stakeholders (drug sellers, CHWs, care-seekers and government officials) reported receiving information about the AXEX intervention; most importantly that drug sellers had been trained on integrated case management of U5 febrile children. Most heard the information from radio talk shows and announcements, community sensitisation workshops, by word-of-mouth from CHWs, drug sellers themselves and from care-seekers with previous contact with study drug shops. A few drug sellers and CHWs reported informing their church congregations.

The care-seekers and CHWs mentioned that the medicines, although not free, were provided at lower prices, as marked on the medicine packs, and study drug shops were marked with the A2L poster for easy identification (FGD1, care-seekers 1, 3, 4, 5; FGD4, CHW6). However, some drug sellers mentioned that the A2L poster caused conflict with some drug shops not in the study. The non-study drug shops either vandalised the A2L posters or transferred them to their premises with a hope to attract customers (IDI, DS8; IDI, DS6).

In the words of a CHW,

You know that there were drug sellers you trained and those you did not train. Now when those you did not train got to know that the prices of the drugs were lower, they knew that they were going to run out of business, so they took the sign posts off (down) from those shops that were part of the project. ... Uhmm (in affirmative) because they knew that they were going to lose clientele once people knew that some drug shops were selling drugs at a cheaper price. (FGD4, CHW6)

A few drug shop sellers felt that dissemination had been inadequate and argued for the use of posters, mass mobilisation and more focus on diagnostic testing of febrile children before treatment (IDI, DS6). Some drug sellers and CHWs stated that some care-seekers over time would test from the drug shops and seek medicines from government health facilities (FGD4, CHW1; IDI, DS11).

\section{PROVIDER INCENTIVES}

All drug shop sellers mentioned that taken together, the acquired competencies in integrated case management of paediatric fevers, presence of novel, effective medicines and diagnostics and perceived affordability of fever-care due to the medicine subsidy enhanced their reputation as health providers within the community.

Drug sellers also stated that adding diagnostic testing to their repertoire of services and insisting on face-to-face interaction with the care-seeker and sick child transformed them from 'mere' sellers to 'bashaho' loosely meaning 'medical doctors' or 'biomedicine experts' who appeared to make decisions based on some judgement. Additionally, drug seller collaboration with key stakeholders-district officials, regulators (MoH, NDA and researchers), and CHWs-served to move them from the margins of legitimacy to insiders of the formal health system. In the drug sellers' and care-seekers' views, the community sensitisation that often referred to the A2L poster that marked study drug shops increased this effect. Care-seekers satisfied with drug shop fever-care recommended their friends and neighbours to seek care from drug shops, thereby increasing their customer numbers and sales.

In the words of drug sellers,

The number (of care seekers) increased ... (pause) because of good services and drugs at a low cost. (IDI, DS2)

On our side, we accessed money. Someone would have a problem and you would solve it, so they would go and tell others and they bring others too. (IDI, DS3)

Drug sellers spontaneously mentioned adding adjunct medicines such as iron supplements and cough syrups to willing caretakers to increase their profit margins, an unintended effect, possibly with negative consequences. 
Contrastingly, care-seekers felt empowered to hold the drug sellers accountable for their prices because of the price labels on intervention medicines.

In the words of CHWs,

When these drugs were brought, they (drugs) helped in reducing the high charges of the health workers in drug shops because they were used to high profits, but the drugs came with recommended sale price tags. So the drug seller would also view it as a challenge because it would reduce the profit margin. (FGD4, CHW1)

I think some feared that they will be caught if they kept charging high prices, may be some of them suspected that we had attended the (iCCM project) training too, so they would charge the exact prices for those drugs. They would only add charges for the other drugs if they were part of your purchases. (FGD4, CHW6)

\section{LINKAGE TO THE FORMAL HEALTH SYSTEM}

Both government officials and drug sellers mentioned that they favoured a recognisable and formal linkage between drug shops and the nearest government HCs.

...The private sector should operate concurrently with the public sector. And the private outlets normally go to where the services are needed. They know where there is a gap and the government cannot provide. (IDI, GO1)

In the words of a drug seller,

So when a child would come with danger signs, I would refer them (to Bwizibwera-the nearest government health centre). Once came a twoyear old baby with danger signs of malaria, I did mRDT and it turned out positive, so I referred this baby to Bwizibwera. (IDI, DS6)

I also went to the government health centre and told them, if they got U5 child with pneumonia symptoms and drugs were out of stock, they could refer them to me. (IDI, DS6)

Drug sellers suggested that government health workers could collaborate more by participating in training of drug sellers and should not be dismissive of drug shops' patient referrals without due diligence. For instance, drug sellers often recommended treatments depending on the amount of money provided by the care-seeker. And thus putting blame squarely on drug sellers for truncated doses or inappropriate treatments did not reflect that reality and was considered unfair by drug sellers.

Government officials, drug sellers, CHWs and careseekers argued that a formal partnership presented mutual advantages; continuity of care for care-seekers, decongestion of government HCs and increased penetration of government-led interventions.

In some cases, the AXEX intervention rode on already existing informal linkages between private providers and government HCs, with examples of dual practice and referral of patients by government health workers to drug shops for medicines.

Eighty percent, if not ninety percent of the people who own those drug shops work in the public sector. It is only of recent that people are emerging to be solely private, but even as we speak seventy or eighty percent work in the public sector. (IDI, GO3)

The AXEX intervention was noted to have initiated patient registry and referral mechanisms at the drug shops, and drug shops were providing monthly reports to the district health management information system. Government officials observed that these interventions were critical to strengthening the underlying linkages between drug shops and the formal district health system.

\section{PERCEIVED EFFICACY OF THE AXEX INTERVENTION}

Drug sellers mentioned that the intervention medicines were efficacious, particularly amoxicillin in pneumonia and zinc/ORS in diarrhoea treatment, respectively. In their view, pneumonia and diarrhoea symptoms resolved in U5 children given these medicines, and faster than when given alternative medicines.

The drugs are also effective so it is helping people, most especially those (medicines) for fast breathing (pneumonia symptoms) and diarrhoea. (IDI, DS1)

The drug sellers noted that the intervention medicines had favourable attributes; the single-dose and colourcoded packaging was easier to handle in distribution and treatment counselling of care-seekers, the dispersible tablets were easy to reconstitute into solutions that were child-appropriate in dosing and administering and thus convenient to use. Care-seekers also explained that the medicines in blister strips and single-dose packs were easier to keep safe than loose tablets, the treatment instructions were easy to understand and children liked their palatable taste. Care-seekers noted the reduction in their cost of treatment for similar illnesses.

The good thing with these drugs is that when you would give them to a child and tell them, "Here, have; they are sweet". They would take them, so they are not sour. (IDI, DS2)

In the words of care-seekers,

The difference is with the prices because previously, you would go to the hospital and find that the money is high and you find yourself paying about Uganda Shillings (UGX) 12000 (USD 4) but now it has changed, the drug seller can give you medicine at reduced prices, so you find that the drugs we used to buy at UGX 12000 are now given at UGX 3000 (USD1). (FGD2, care-seeker 3)

The drugs they give us cure the child. So whether it (the cost) is much (high) or less, it still cures. (FGD2, care-seeker 5)

Most drug sellers mentioned that the diagnostic tests were transformative to their practice. The mRDTs and respiratory rate timers were easy to use and performed well. A negative malaria test indicated that the child did not have malaria and the respiratory timer detected pneumonia symptoms. 
The RDTs quickly give you results. And RDT's do not need electric power... with the way we were trained; I learned that you can carry out tests on children even without microscopes. (IDI, DS3)

However, there were complaints about discrepancies between the RDT results at the drug shops and malaria tests done at other private facilities. Overall, drug sellers observed that the AXEX intervention had contributed to saving children's lives and requested for an extension of the project life and expansion of services to cover febrile illnesses in adults.

\section{DISCUSSION}

The AXEX intervention was found to increase appropriate treatment of symptoms of pneumonia, malaria and diarrhoea substantially. It is an example of a multicomponent intervention towards creating a functioning health market, which provides equitable access to good quality, efficacious medicines while maintaining transparency and accountability. Care-seeker expectations of quality of fever care at drug shops were reconfigured, from trial and error to care that was based on definitive knowledge based on rapid tests. The medicines provided in the AXEX intervention had attributes that improved regulatordrug seller interaction, and care-seeking behaviour. The presence of quality-assured single-dose packaged, colourcoded medicines that were easy to handle at drug shops and promoted patient adherence ${ }^{50}$ to prescribed doses was appreciated by regulators and care-seekers, although for different reasons. On the regulator's side, these products met medicine packaging standards and regulations ${ }^{51}$ and encouraged dispensing of full treatment courses and maintaining good drug shop records. Care-seekers referred to the enhanced treatment experience due to the convenience of handling single-dose prepackaged medicines and the palatable taste of medicines to the children as being important to the children's adherence to treatment. This care-seeker experience and interpretation is consistent with observations by anthropological researchers who have inquired into the human dimension of medicine access, which goes beyond the product's efficacy and touches on perceived quality and acceptability of treatment (including social and cultural dimensions). ${ }^{452}$

Pre- $A X E X$ intervention, drug shops were largely seen as outside the formal system and suspicious of regulation, regulators looked on them as opportunistic profit makers, CHWs too largely looked at them as this and communities went mostly to get medicines on demand. However, the medicines' and diagnostics' essence as 'materia medica' could explain the observations from the current study, of how the presence of medicines and diagnostics transformed the relationship between drug sellers and their customers and other stakeholders, ${ }^{4}$ potentially shifting drug sellers from outsider to insider in the formal health system. Other intervention studies in drug shops in Uganda have reported similar findings. ${ }^{58} 40$ In the study by Hutchinson et al, drug sellers demonstrated their ability to test blood by using visibly medicalised itemsgloves, lancets, mRDTs-considered solely the domain of trained, formal health workers. This reinforced careseeker confidence in drug seller skill and ability. ${ }^{38}$ Presence of diagnostics engendered trust between drug sellers and care-seekers, and created legitimacy, thereby bringing the drug shops closer to the formal health system. $^{538}{ }^{40}$ However, the current study is different as it evaluated a multicomponent intervention with a franchise system, components to improve health market regulation and forge linkages with the formal health system, and it evaluated the iCCM of childhood febrile illnesses rather than just malaria tests.

The AXEX intervention used community sensitisation through radio talk shows, radio messages and workshops for CHWs and local leaders. The CHWs, local leaders and care-seekers then participated in informing individual households with U5 children by word-of-mouth. The drug shops studied here were marked with a franchisee A2L logo for easy identification and community awareness. Another component was the provision of medicine subsidies as incentives to drug sellers and communities to participate. Recommended retail prices were marked on medicine packs which engendered care-seekers to enact their agency in negotiations with drug sellers during the care-seeking process. This contributed to creating transparency among the stakeholders and accountability of drug sellers to their communities, helping the intervention achieve its objectives. ${ }^{23}$

The intervention resulted in the inclusion of the informal market into systems of regulation through stakeholder acceptance, which matched reality rather than ignoring the existence of a market and pretending it did not exist. In the current study, regulation of the retail market was approached as an outcome of a series of relationships between state agencies (NDA, MoH, PSU and local government), private drug outlets and beneficiary communities ${ }^{53}$ to shape the norms, and rules-formal and informal-that influence interactions between drug sellers and care-seekers and other key players. Additionally, sector-specific regulations and standards (such as requiring a NDA licence) were enacted in the AXEX intervention as de facto while modifying other aspects of regulation to bring them closer to what was de jure considered legitimate (expanding the legal permits to include antimicrobials and diagnostics and training underqualified drug sellers) in a retail market such as in South Western Uganda. ${ }^{25}$

While the earlier market had enabled physical access, questions remained about quality, prescribing patterns and overuse of antimicrobials in febrile children who may not have needed them. The AXEX intervention was taken up by drug sellers, and its implementation in drug shops was accepted by other stakeholders within the study area. As a result, children with febrile illnesses could be assessed in an integrated way for common childhood illnesses. Those diagnosed with uncomplicated malaria, ARI or diarrhoea 
obtained recommended treatments according to the national iCCM algorithm. Similar findings are reported by Hutchinson $e t a l,{ }^{40}$ who found that good diagnostic ability was closely associated with ethical and effective practice. The difference with the current study is that the study by Hutchinson $e$ al assessed only malaria tests rather than the effect of an iCCM intervention that offers additional options for the health worker including respiratory timers (to assess for pneumonia symptoms), antibiotic medicines and diarrhoeal treatment.

Coupled with training, the provision of drugs and commodities and information, helped create incentives for drug shops to allow or cede to regulation, together this increased legitimacy and status and helped build trust, both between regulators and drug shops and between drug shops and care-seekers. The authors portend that the approach to implementation of the AXEX intervention, analysing relevant stakeholders and engaging them along with the multipronged character of the intervention led to conditions necessary for establishing trust among the actors. Trust is an important ingredient for cooperative relations. ${ }^{54}$ It is a precursor to aligning divergent interests among multiple actors towards collective action. Above all, trust enables actors to assimilate all evidence and secures communication and dialogue. ${ }^{54}$

Whereas supply of medicines, diagnostics and healthcare is necessary, acceptance and use by care-seekers is vital to complete the loop of effective fever care delivery (figure 1). The trust established enhanced the quality of interaction between drug seller and care-seekers, a prerequisite for greater disclosure and behavioural change by care-seekers. Similar effects of a trusting provider/patient relationship have been described by Mechanic. ${ }^{556}$ As reasoned by other scholars, ${ }^{57}$ the provider/patient relationship is shaped by the institutions embedded within the health system, underscoring the importance of support functions (figure 1); namely, training of drug sellers, involvement of district officials and formal HCs, community sensitisation and the presence of medicines and supplies. The interplay among all the AXEX intervention components-presented in the theoretical framework (figure 1)-created conditions where drug sellers' behaviours were aligned with careseekers interests.

The success of the AXEX intervention in improving the functioning of drug shops in a pluralistic health market also brings to light critical issues for consideration by health system analysts. First is the need for caution in overconfidence of drug sellers which could manifest in prescribing beyond what they are trained to. Drug sellers applied diagnostic testing to guide their treatment decisions. Care-seekers on the other hand changed their care-seeking practices and expectations of the care provided by drug sellers. Thus, the interaction between drug sellers and care-seekers was elevated from a purely 'economic or commercial transaction' to an at least partially 'clinical or therapeutic transaction' as described by Cross and MacGregor. ${ }^{58}$ Whereas, this was a welcome observation in the current study, the authors call for caution since drug sellers could use this legitimacy to go beyond their basic training and undermine the public health sector and abuse public trust.

Second, how does one sustain aspects of the AXEX intervention responsible for its success beyond the project duration? These include subsidies for diagnostics and medicines, which maybe essential to maintain affordability by care-seekers, the co-production of regulation by multiple stakeholders including government officials, CHWs, research staff, caretakers, communities and drug sellers and regulation, of selling other drugs-vitamin and mineral formulas and supplements of little therapeutic value-as a drug seller coping mechanism to remain profitable in a rapidly changing retail health market. A possible approach to sustaining the subsidies for diagnostics and medicines is to expand the Affordable Medicines Facility for Malaria ${ }^{59}$ to include other commodities used in the integrated management of paediatric febrile illness. Peters $e t a t^{60}$ and Leonard $e t$ $a b^{\tilde{3}}$ suggest approaches that exploit the roles of actors towards co-production to regulate health markets.

Third, it is important to address tensions in the community that arise from drug shops left outside the AXEX intervention, CHWs and government HCs. CHWs felt aggrieved that the iCCM intervention designed to be implemented by them had been taken to drug sellers probably due to fear of loss of their status and power in the community.

\section{CONCLUSION}

Drug shops in rural areas remain an important source of care for U5 children ${ }^{61}$ and should be part of the solution as low-income countries aim to achieve Universal Health Coverage. ${ }^{62}$ We intervened to create a functional health market that improved access to life-saving medicines and technologies for U5 febrile children using a health systems approach $^{49}$ by adopting a health market systems framework. ${ }^{23}$

The AXEX intervention was beneficial as it acted on the legitimacy and reputation of drug sellers, and it provided a platform on which trust between drug sellers and regulators, and drug sellers and care-seekers was enacted and allowed to thrive. Trust enabled improvement in the quality of interaction among the multiple actors in the retail health market, promoted behaviour change among drug sellers and care-seekers and created conditions for convergence of their interests. Whereas drug seller reputation is important for their existence and profitability, it is also difficult to manage given the information asymmetry that exists in such health markets.

Drug shops were part of complex retail health systems with multiple actors. The actors and the system adapted. Cognisant of the complex multiple factors that influence drug seller practices ${ }^{63}$ and the shortcomings of single interventions in such retail health markets, ${ }^{63-65}$ the AXEX intervention, was a multicomponent intervention as reported in this paper. The importance and advantage of a multipronged intervention for similar markets cannot be overemphasised. It enacted realistic regulation to help increase 
and maintain quality, sustain provision of drugs and commodities as well as incentives to sellers to comply and users to come to licensed drug shops along with communication to enhance trust in drug shops among communities. Each of these, done alone would not have had similar effects. This conclusion is consistent with other researchers who have argued against single interventions that focus on knowledge alone ${ }^{63}$ or problematise need narrowly and offer enhanced supply as the sole solution ${ }^{66}$ or interventions that conceptualise regulation as a purely command and control activity. ${ }^{23} 53$ The AXEX intervention was thus more than the sum of its parts.

We therefore recommend that interventions in retail health markets should comprise components that target the multiple actors or influences that shape that market. Examples could include inputs for service delivery, consumer empowerment and demand generation, modifications in regulation or the creation of conditions for co-creation of regulation. Second, multicomponent health system interventions are complex to implement and also create complexity in their evaluation. Their evaluation should be based in realism and should include analysis of the process of implementation. When medicines and technologies are one of the components, they should not be analysed only as products, but rather as items that encapsulate interests of different actors, some of which maybe converging with or competing against overall societal goals.

\section{Author affiliations \\ ${ }^{1}$ Department of Pharmacy, Makerere University College of Health Sciences, Kampala, Uganda \\ ${ }^{2}$ School of Public Health, Makerere University College of Health Sciences, Kampala, Uganda \\ ${ }^{3}$ Department of Women's and Children's Health, International Maternal and Child Health Unit, Uppsala University, Uppsala, Sweden \\ ${ }^{4}$ University of Witwatersrand, School of Public Health, Johannesburg, South Africa \\ ${ }^{5}$ UNICEF, Health Section, New York, USA \\ ${ }^{6}$ Department of Health System Governance and Financing, Health System Governance, Policy and Aid Effectiveness, WHO, Geneva, Switzerland \\ ${ }^{7}$ WHO Alliance for Health Policy and Systems Research, Geneva, Switzerland}

Correction notice This article has been corrected since it first published. The wording in the open access statement has been corrected.

Acknowledgements This research was supported by the Alliance for Health Policy and Systems Research, World Health Organization, with funding from DFID. The authors would like to thank the drug sellers, care-seekers, community health workers, government officials who participated in the study, district health team of Mbarara for supporting implementation of the study, the research assistant and Brocher Foundation of Hermance, Switzerland for offering the main author a researcher residence to analyse and write the first draft of this paper.

Contributors FEK, HW, SP and ZS designed and conceptualized the study. FEK, HW and ZS developed and refined the study tools. FEK and CM conducted interviews, discussed emerging issues and modified topic guides during data collection. FEK, CM and EWJ read the transcripts and developed initial codes. FEK and $\mathrm{CM}$ developed mutually agreed codes, themes and categories. FEK, CM, EWJ and ZS contributed to data analysis and interpretation. FEK wrote the first paper draft. FEK,MB and ZS revised the first draft. FEK, CM, EWJ, SP, HW, MB and ZS reviewed and contributed to writing the paper. All authors read and approved the final manuscript.

Funding The study was supported by WHO Alliance for Health Policy and Systems Research, Einhorn Family Foundation, Pehr Lagermans Family, Sweden, Swedish
Science Council and Uppsala University. These organisations had no role in the design, implementation, interpretation or reporting of the findings.

Disclaimer The authors are staff members of the WHO. The authors alone are responsible for the views expressed in this publication and they do not necessarily represent the views, decisions or policies of the WHO.

Competing interests None declared.

Ethics approval WHO Ethics Review Committee, Makerere University School of Public Health Higher Degrees and Research Ethics Committee (IRB00011353) and the Uganda National Council for Science and Technology (HS1385).

Provenance and peer review Not commissioned; externally peer reviewed.

Open Access This is an open access article distributed under the terms of the Creative Commons Attribution-NonCommercial IGO License (CC BY-NC 3.0 IGO) which permits use, distribution, and reproduction for non-commercial purposes in any medium, provided the original work is properly cited. In any reproduction of this article there should not be any suggestion that WHO or this article endorse any specific organization or products. The use of the WHO logo is not permitted. This notice should be preserved along with the article's original URL. See: https:// creativecommons.org/licenses/by-nc/3.0/igo

(c) World Health Organization [2017]. Licensee BMJ.

\section{REFERENCES}

1. UNICEF. Child Survival: under-five mortality - Current status and Progress; Cause of death. 2016a https://data.unicef.org/topic/childsurvival/under-five-mortality/ (cited 2 Apr 2017).

2. Clinton Health access Initiative \& Coalition for Health Promotion and Social Development Uganda, Assessment of the management of diarrhoea, pneumonia and malaria in children under-5 in Uganda. Kampala: CHAI, 2014.

3. Awor P, Wamani $\mathrm{H}$, Bwire $\mathrm{G}$, et al. Private sector drug shops in integrated community case management of malaria, pneumonia, and diarrhea in children in Uganda. Am J Trop Med Hyg 2012;87(5 Suppl):92-6.

4. Whyte SR, Van der Geest S, Hardon A, eds. Social lives of medicines. Cambridge: Cambridge University Press, 2002.

5. Chandler $\mathrm{Cl}$, Hall-Clifford $\mathrm{R}$, Asaph $\mathrm{T}$, et al. Introducing malaria rapid diagnostic tests at registered drug shops in Uganda: limitations of diagnostic testing in the reality of diagnosis. Soc Sci Med 2011;72:937-44.

6. Rutebemberwa E, Pariyo G, Peterson S, et al. Utilization of public or private health care providers by febrile children after user fee removal in Uganda. Malar J 2009;8:45.

7. Mol A. The logic of Care. Health and problem of patient choice. London: Routledge, 2008.

8. van der Geest S. Self-care and the informal sale of drugs in south Cameroon. Soc Sci Med 1987;25:293-305.

9. Whyte SR. Pharmaceuticals as folk medicine: transformations in the social relations of health care in Uganda. Cult Med Psychiatry 1992;16:163-86.

10. Birungi $H$, Mugisha F, Nsabagasani X, et al. The policy on publicprivate mix in the ugandan health sector: catching up with reality. Health Policy Plan 2001;16(Suppl 2):80-7.

11. Konde-Lule J, Gitta SN, Lindfors A, et al. Private and public health care in rural areas of Uganda. BMC Int Health Hum Rights 2010;10:29.

12. Ferrinho P, Van Lerberghe W, Fronteira I, et al. Dual practice in the health sector: review of the evidence. Hum Resour Health 2004;2:14.

13. McPake B, Asiimwe D, Mwesigye F, et al. Informal economic activities of public health workers in Uganda: implications for quality and accessibility of care. Soc Sci Med 1999;49:849-65.

14. Adome RO, Whyte SR, Hardon A. Popular pills: community drug use in Uganda. Amsterdam: Het Spinhuis, 1996.

15. Mogensen HO. Finding a path through the health unit: practical experience of ugandan patients. Med Anthropol 2005;24:209-36.

16. Uganda Bureau of Statistics (UBOS). The National Population and Housing Census 2014 - Main Report. Kampala, Uganda: UBOS, 2016.

17. Ministry of Health (Uganda), Annual Health Sector Performance Report - Financial Year 2014/2015. Government of Uganda: Kampala, 2015.

18. Uganda Ministry of Health, Annual Health Sector Performance Report - Financial Year 2015-2016. Kampala: Ministry of Health, 2016. 
19. UNICEF, Levels and Trends in Child Mortality. Report 2015. Estimates developed by the UN Interagency Group for Child Mortality estimation. New York, USA, 2015c.

20. Ministry of Health (Uganda), the Uganda Malaria Reduction Strategic Plan 2014 - 2020. Kampala, Uganda: Ministry of Health, 2014a

21. World Health Organization. World Malaria Report 2015. WHO Global Malaria Programme: France, 2015.

22. Wallman S, Baker M. Which resources pay for treatment? A model for estimating the informal economy of health. Soc Sci Med 1996;42:671-9.

23. Bloom G, Henson S, Peters DH. Innovation in regulation of rapidly changing health markets. Global Health 2014;10:53

24. Sheikh K, Saligram PS, Hort K. What explains regulatory failure? analysing the architecture of health care regulation in two indian states. Health Policy Plan 2015;30:39-55.

25. Goodman C, Kachur SP, Abdulla S, et al. Drug shop regulation and malaria treatment in Tanzania--why do shops break the rules, and does it matter? Health Policy Plan 2007;22:393-403.

26. Peters $\mathrm{DH}$. The application of systems thinking in health: why use systems thinking? Health Res Policy Syst 2014;12:51.

27. Ministry of Health (Uganda), Integrated Community Case Management of Childhood Malaria, Pneumonia and Diarrhoea; Implementation Guidelines, Child Health. Kampala, Uganda: Ministry of Health (Uganda), $2010 \mathrm{~b}$.

28. WHO \& UNICEF. WHO/UNICEF Joint Statement: integrated Community Case Management (iCCM); An equity-focused strategy to improve access to essential treatment services for children. Geneva: WHO/UNICEF, 2012.

29. Mupara LU, Lubbe JC. Implementation of the Integrated Management of Childhood Illnesses strategy: challenges and recommendations in Botswana. Glob Health Action 2016;9:29417.

30. Kamya MR, Arinaitwe E, Wanzira $\mathrm{H}$, et al. Malaria transmission, infection, and disease at three sites with varied transmission intensity in Uganda: implications for malaria control. Am J Trop Med Hyg 2015;92:903-12.

31. Uganda Bureau of Statistics (UBOS) and ICF International, Uganda Malaria Indicator Survey 2014-15: Key Indicators. Kampala, Uganda, and Rockville, Maryland, USA: UBOS and ICF International, 2015.

32. Parker M, Harper I. The anthropology of public health. J Biosoc Sci 2006;38:1-5.

33. Kitutu FE. Integrated Community Case Management by Drug Sellers increases Appropriate treatment of Pediatric Febrile illness in South Western Uganda: A quasi experimental study, Makerere University \& Uppsala University, 2017.

34. Oakley A, Strange V, Bonell C, et al.Process evaluation in randomised controlled trials of complex interventions. $B M$ 2006;332:413-6.

35. Merton RK. The unanticipated consequences of purposive Social Action. Am Sociol Rev 1936;1:894-940.

36. Kleinman A. Four social theories for global health. Lancet 2010;375:1518-9.

37. Bloom G, Standing $\mathrm{H}$, Lucas $\mathrm{H}$, et al. Making health markets work better for poor people: the case of informal providers. Health Policy Plan 2011;26(Suppl 1):i45-i52.

38. Hutchinson E, Chandler C, Clarke S, et al. 'It puts life in us and we feel big': shifts in the local health care system during the introduction of rapid diagnostic tests for malaria into drug shops in Uganda. Crit Public Health 2015;25:48-62.

39. Mbonye AK, Clarke SE, Lal S, et al. Introducing rapid diagnostic tests for malaria into registered drug shops in Uganda: lessons learned and policy implications. Malar J 2015;14:448.

40. Hutchinson $\mathrm{E}$, Hutchison $\mathrm{C}$, Lal S, et al. Introducing rapid tests for malaria into the retail sector: what are the unintended consequences? BMJ Glob Health 2017;2:e000067.

41. Mohanan M, Giardili S, Das V, et al. Evaluation of a social franchising and telemedicine programme and the care provided for childhood diarrhoea and pneumonia, Bihar, India. Bull World Health Organ 2017:95:343-52.

42. Young M, Wolfheim C, Marsh DR, et al. World Health Organization/ United Nations Children's Fund joint statement on integrated community case management: an equity-focused strategy to improve access to essential treatment services for children. Am J Trop Med Hyg 2012;87(5 Suppl):6-10.

43. Bloom G. Engaging with Health Markets in low and Middle-income countries. IDS Working Paper 443, I.o.D. Studies. London, UK: IDS, 2014.

44. Hyder A, Syed S, Puvanachandra P, et al. Stakeholder analysis for health research: case studies from low- and middle-income countries. Public Health 2010;124:159-66.

45. Pope C, Mays N, eds. Qualitative research in health care.3rd edn London: Wiley, 2006.

46. ICT Services and System Development and Division of Epidemiology and Global Health. OpenCode 4.03. Umea : Umea University, 2013. http://www.phmed.umu.se/enheter/epidemiologi/forskning/opencode/ (cited 1 jan 2016).

47. Graneheim UH, Lundman B. Qualitative content analysis in nursing research: concepts, procedures and measures to achieve trustworthiness. Nurse Educ Today 2004;24:105-12.

48. Adam T, de Savigny D. Systems thinking for strengthening health systems in LMICs: need for a paradigm shift. Health Policy Plan 2012;27(Suppl 4):iv1-iv3.

49. Atun R. Health systems, systems thinking and innovation. Health Policy Plan 2012;27(Suppl 4):iv4-iv8.

50. Yeboah-Antwi K, Gyapong JO, Asare IK, et al. Impact of prepackaging antimalarial drugs on cost to patients and compliance with treatment. Bull World Health Organ 2001;79:394-9.

51. World Health Organization. WHO Technical Report Series No 902 - Guidelines on packaging of pharmaceutical products. Geneva, Switzerland: WHO, 2002.

52. Bigdeli M. Access to medicines in low- and middle-income countries: a health system approach. Conceptual framework and practical applications, in Ecole de Sante Publique. Bruxelles: Universite libre de Bruxelles, 2015.

53. Leonard DK, Bloom G, Hanson K, et al. Institutional Solutions to the Asymmetric Information Problem in Health and Development Services for the Poor. World Dev 2013;48:71-87.

54. Misztal BA. Trust in modern societies: the search for the bases of moral order. Cambrigde: Polity Press, 1996.

55. Mechanic D. Changing medical organization and the erosion of trust. Milbank Q 1996;74:171-89.

56. Mechanic D. Public trust and initiatives for new health care partnerships. Milbank Q 1998;76:281-302.

57. Gilson L. Trust and the development of health care as a social institution. Soc Sci Med 2003;56:1453-68.

58. Cross J, MacGregor HN. Knowledge, legitimacy and economic practice in informal markets for medicine: a critical review of research. Soc Sci Med 2010;71:1593-600.

59. Deelder W, Lang K. "Saving lives and buying time": Lessons in good subsidy design from the Affordable Medicines Facility - Malaria (AMFm), Global Subsidies Initiative. Geneva: International Institute of Sustainable Development, 2010.

60. Peters DH, El-Saharty S, Siadat B. Janovsky, K. and Vujicic M.improving Health Service delivery in developing countries: from evidence to Action. Washington DC: The World Bank, 2009.

61. Bustreo F, Harding A, Axelsson H. Can developing countries achieve adequate improvements in child health outcomes without engaging the private sector? Bull World Health Organ 2003;81:886-95.

62. Basu S, Andrews J, Kishore S, et al. Comparative performance of private and public healthcare systems in low- and middle-income countries: a systematic review. PLoS Med 2012;9:e1001244.

63. Tawfik Y, Northrup R, Prysor-Jones S. Utilizing potential of the formal and informal private practitioners in child survival: survival analysis and summary of promising interventions, support for analysis and research in Africa (SARA) Project. Washington DC: SARA, 2002.

64. Rowe AK, de Savigny D, Lanata CF, et al. How can we achieve and maintain high-quality performance of health workers in low-resource settings? Lancet 2005;366:1026-35.

65. Alexander K, Rowe AK. Review of Strategies to Improve Health Care Provider Performance Improving Health Service Delivery in Developing Countries - From Evidence to Action. Washington DC: The World Bank, 2009.

66. Pritchett L, Woolcock M. Solutions when the solution is the Problem: arraying the Disarray in Development. World Dev 2004;32:191-212. 